\title{
Inadequate medical treatment of patients with coronary artery disease by primary care physicians in Germany
}

\author{
B. Bischoff, S. Silber, B.M. Richartz, L. Pieper, J. Klotsche, H.-U. Wittchen, for the DETECT \\ study-group
}

\begin{abstract}
Summary
Aims The DETECT study was performed to obtain representative data about the frequency, distribution, and treatment of patients with coronary artery disease (CAD) in the primary care setting in Germany.

Methods and results The DETECT study was a cross-sectional clinical- epidemiological survey of a nationally representative sample of 3795 primary care offices and 55518 patients. Overall, $12.4 \%$ of patients were diagnosed with CAD. Stable angina pectoris and myocardial infarction were the most frequent $(4.2 \%)$ subgroups, followed by status post ( $\mathrm{s} / \mathrm{p})$ percutaneous coronary interventions (PCI, $3.0 \%)$ and s/p coronary bypass surgery (2.2\%). Patients with CAD were prescribed AT1 receptor antagonists (in 19.4\% of cases), beta blockers (57.2\%), ACE inhibitors (49.9\%), antiplatelet agents (52.7\%), statins (43.0\%), and long-term nitrates (24.5\%). When comparing all CAD patients with social health care insurance to those who had private insurance, private patients had significantly higher rates of revascularisation procedures and use of preventive medications.

Conclusion Great potential remains for improving secondary prevention in primary care in Germany to reduce the risk of further coronary or vascular events, especially in patients with social health care insurance.
\end{abstract}

Key words: Coronary heart disease, prevalence, secondary prevention, primary care

\section{Introduction}

Cardiovascular disease is a major cause of death in most European populations [1, 2]. In Germany, the most common causes of death in 2003 were chronic ischaemic heart disease (19.1\%) and acute myocardial infarction (7.5\%, Table 1) [3]. More women than men die from coronary artery disease (CAD). Therefore, in women too, CAD is the leading cause of death. The chance a German woman will die from CAD is seven times higher than the chance she'll die from breast cancer (Table 1).

In addition to coronary bypass surgery and percutaneous coronary interventions (PCI) [4, 5], treatment with appropriate medications can reduce mortality and/or morbidity in patients with CAD. Examples include platelet inhibitors, beta blockers, ACE inhibitors, and statins [1]. The recent survey of the European Society of Cardiology (ESC) on coronary revascularisation in 5619 patients revealed that $95 \%$ received antithrombotic drugs, $74 \%$ received beta blockers, 57\% received ACE inhibitors, and 67\% received statins at discharge [5]. Another recent ESC survey covering 3779 patients with stable angina showed that $78 \%$ of these patients received aspirin, 67\% received beta blockers, 37\% received ACE inhibitors, and $48 \%$ received statins [6]. In this European survey, however, only 144 patients from Germany were enrolled.

The existing data regarding the prevalence of coronary heart disease in Germany are severely limited. Therefore, the purpose of the DETECT study was to obtain representative data about the frequency, distribution, and treatment of patients with CAD in the German primary care setting. 


\section{Methods}

DETECT (Diabetes cardiovascular-risk Evaluation: Targets and Essential data for Commitment of Treatment) is a three-stage, cross-sectional clinical-epidemiological study with a prospective-longitudinal component in a nationally representative sample of 3795 primary care settings and 55518 patients. The overall physician response rate to the survey was $95.5 \%$. A standardised assessment was completed for each patient, including diagnostic screening measures (i.e., blood pressure, heart rate, body mass index, and waist circumference) and questionnaires were completed for patients and their physicians. A subsample of 7519 patients also completed a standardised laboratory screening program with followup after 12 months. Data were weighted to adjust for non-response, regional distribution, and attrition. Further details about the study have been published previously [7, 8].

All prevalence estimates reported in this paper were based exclusively on clinical diagnoses or specifications rated as 'definite' by the treating physician ( $\mathrm{n}=55518)$. Patients with a definite diagnosis of CAD were placed into the following six subclassifications: stable angina, unstable angina, myocardial infarction, PCI, coronary bypass surgery, and other. All physicians in DETECT practiced in the primary care setting in Germany.

Within the standardised clinical assessment, physicians supplied data about the actual drug therapy the patient received. All prescription rates were based on patients with the definite diagnosis of CAD receiving a known actual medication $(n=6569)$. Regarding the prescription rates for CAD patients with a different number of comorbid diseases, just the following comorbid diseases were considered: Diabetes mellitus, hypertension, and hyperlipidaemia. Whereas the diagnoses of hypertension and hyperlipidaemia were based solely on a physician's clinical diagnosis, a patient was considered to have diabetes mellitus either if the patient was diagnosed clinically or if the patient received a prescription for an antidiabetic drug. The prevalence estimates derived from the study were based on the physician diagnoses. Using descriptive statistics, we compared the distributions of variables among all categories. Associations were estimated using logistic regression models. All statistical analyses were conducted with the software package STATA 8 [9].

\section{Results}

\section{Prevalence of $C A D$}

Table 2 shows the prevalence of CAD and its subgroups broken out by age and gender. Overall, $12.4 \%$ of patients (6895/55 518) were diagnosed with CAD. Stable angina pectoris and myocardial infarction were the most frequent subgroups (4.2\%), followed by s/p PCI (3.0\%), and s/p coronary bypass surgery (2.2\%). The ratio between stable angina and unstable angina was 3.8. Table 2 also reveals an age-related increase in all diagnoses and specifications. Furthermore, the prevalence rates for all diagnoses and specifications were higher in men compared to women in most age groups.

\section{Medications in patients with CAD}

Table 3 lists the intake frequency of antiplatelet drugs, beta blockers, ACE inhibitors, AT1 receptor antagonists, statins, and long-term nitrates in patients with CAD, both as a group and within each subgroup. The prescription rates of these drugs, with the exception of AT1 
receptor antagonists and long-term nitrates, showed a trend toward higher use in patients after myocardial infarction, PCI, and coronary bypass surgery than in patients with stable or unstable angina.

We observed significant differences in prescribed medications between CAD patients with social health care insurance and those with private health care insurance. Whereas CAD patients with social health care insurance were prescribed ACE inhibitors (social: 50.3\%; private: $41.0 \%$; $\mathrm{OR}=0.48 ; \mathrm{P}<0.001$ ) and long-term nitrates (social: $25.0 \%$; private: $16.2 \%$; $\mathrm{OR}=0.41 ; \mathrm{P}<0.0001$ ) more frequently than CAD patients with private health insurance, the opposite was true for AT1 receptor antagonists (social: 19.1\%; private: 29.5\%; OR=1.35; $\mathrm{P}<0.001$ ), beta blockers (social: 57.1\%; private: $63.8 \%$; $\mathrm{OR}=0.76 ; \mathrm{P}<0.001$ ), antiplatelet agents (social: $52.5 \%$; private: $56.1 \%$; $\mathrm{OR}=0.75$; $\mathrm{P}<0.001$ ), and statins (social: $42.6 \%$; private: $50.6 \%$; $\mathrm{OR}=0.93 ; \mathrm{P}<0.173$ ).

Male $(\mathrm{m})$ patients received drugs fromthe following classes significantly more oftenthan female (f) patients: beta blockers (m: 60.8\%; f: 52.3\%; OR=1.26; $\mathrm{P}<0.001$ ), ACE inhibitors (m: 53.0\%; f: 45.7\%; OR=1.50; $\mathrm{P}<0.001$ ), antiplatelet agents (m: 57.2\%; f: 46.5\%; OR=1.85; $\mathrm{P}<0.001$ ), and statins (m: 46.3\%; f: 38.5\%; OR=1.62; $\mathrm{P}<0.001$ ). Female patients received AT1 receptor antagonists (m: 18.1\%; f: 21.2\%; OR=1.19; $\mathrm{P}<0.001)$ and long-term nitrates (m: 23.5\%; f: 25.8\%; OR=1.55; $\mathrm{P}=0.000$ ) significantly more frequently than male patients.

Figure 1 shows differences in medication groups according to age and gender. For all medication groups, a relationship between prescription rates and age is clearly visible - most impressive in a linear manner for nitrates.

Figure 2 lists the prescription rates for CAD patients with the comorbid diseases diabetes mellitus, hypertension, and hyperlipidaemia. It is statistically significant that physicians prescribe more secondary preventive medications in CAD patients with a higher comorbidity ( $\mathrm{P}<0.0005$ for all medications except nitrates).

\section{Revascularisation rates in patients with $C A D$}

CAD patients underwent PCI and coronary bypass surgery in $23.8 \%$ and $17.4 \%$ of cases, respectively. After PCI, $15.9 \%$ of patients still had stable angina compared to $9.6 \%$ after coronary bypass surgery. The highest revascularisation rates were observed in patients with s/p myocardial infarction (42.3\% in PCI and $29.7 \%$ in coronary bypass surgery). Male CAD patients received PCI and coronary bypass surgery more often than female CAD patients (PCI: $29.5 \%$ vs $16.0 \%$, OR=2.19, $\mathrm{P}<0.001$; coronary bypass surgery: $23.1 \%$ vs $9.8 \%$, $\mathrm{OR}=2.77, \mathrm{P}<0.001)$. CAD patients with private health care insurance received $\mathrm{PCI}$ and coronary bypass surgery more often than CAD patients with social health insurance (PCI: $33.7 \%$ vs $23.3 \%$, $\mathrm{OR}=0.60, \mathrm{P}<0.001$; coronary bypass surgery: $22.7 \%$ vs $17.2 \%$, $\mathrm{OR}=0.71$, $\mathrm{P}=0.016)$. 


\section{Discussion}

\section{Prevalence of $C A D$}

According to the results of the DETECT study, nearly every eighth patient in German primary care offices is a patient with established CAD. As such, effective secondary prevention is of utmost importance. Comparing the prevalence of CAD in primary care offices in the DETECT study with the prevalence of CAD in the general population in the German Federal Survey [10], the DETECT study found slightly higher prevalence rates (Fig. 3). In DETECT, stable angina was 3.8 times as frequent as unstable angina. This result is comparable to the ratio of 4.55 that was calculated by the Equinox Group [11]. It should be noted as a limitation that the prevalence rates - with the exception of diabetes mellitus - were based exclusively on physician diagnoses. Given this limitation, the actual prevalence would be expected to be slightly higher than the reported rates.

\section{Medication prescription rates}

A recently published study showed that the use of multiple evidence-based classes of cardiovascular medications (i.e., antiplatelet, lipid-lowering, beta blockers, and ACE inhibitors) is associated with improved outcome (free of death or myocardial infarction) [12]. In our own experience in a single-centre survey in patients undergoing PCI in the year 2000, $89 \%$ of the referred patients were on antithrombotic medications, $65 \%$ were on beta blockers, $43 \%$ were on ACE inhibitors, and $46 \%$ were on statins [13]. The corresponding ranges from eleven studies of inpatients published in the period between 1997 and 2000 were $77-100 \%$ for antithrombotic medications, 30-80\% for beta blockers, $10-72 \%$ for ACE inhibitors, and 13$77 \%$ for statins [13].

The pivotal data for Europe regarding prescription rates in CAD patients before hospital discharge were derived from the EUROASPIRE I and II studies [14]. Table 4 summarises the key data from EUROASPIRE I and II as compared to the DETECT results. Although considerable improvement in the prescription rates of beta blockers, ACE inhibitors, and statins occurred between 1995/1996 (EUROASPIRE I) and 1999/2000 (EUROASPIRE II), the corresponding prescription rates in Germany in 2003 (DETECT) remained below the European average, especially in terms of prescriptions of antiplatelet medications, beta blockers, and statins (Table 4). In the UK, Brady et al. [15] observed similar prescription rates of antiplatelet agents, but clearly lower prescription rates of beta blockers (21.4\%), ACE inhibitors (13.4\%), and statins (16.2\%) in 24431 patients with a diagnosis of CAD in primary care.

Several publications have reported that men receive adequate treatment for CAD more often than women [16-18]. This study also shows lower prescription rates of beta blockers, ACE inhibitors, antiplatelet agents, and statins in women than in men, even though the prevalence rates of diabetes mellitus, hypertension, and hyperlipidaemia are similar in both genders. This result indicates a bias in prescription behaviour between male and female patients treated in primary care [19]. One reason may be that physicians in general considered the male patient to be at higher risk than the female patient [16]. On the other hand, female CAD patients received nitrates more often than male CAD patients, possibly reflecting their lower rates of PCI (16.0\% vs $29.5 \%)$ and lower rates of bypass surgery (9.8\% vs $23.1 \%)$. The higher rates of AT1 receptor inhibitors may possibly be related to a higher incidence of ACE-inhibitor side effects in women [20]. The debate regarding the difference in drug prescriptions between CAD patients with social health care insurance and private insurance is ongoing. Although the 
cost-containment restrictions ("medication budget") for primary care physicians in Germany might explain the documented failure of guideline-oriented medications, the undertreatment even with acetylsalicylic acid shows that economic restrictions are not the sole explanation.

The prescription rates of all drugs essential to improving prognosis of patients with CAD is correlated with the number of comorbidities (diabetes, hypertension, hyperlipidaemia). This situation reflects the fact that doctors are aware of the increasing risk these patients have for further cardiovascular events. On the other hand, even coronary patients with no comorbidity do need the full combination of antiplatelet agents, statins, beta blockers, and ACE inhibitors/ AT1 receptor antagonists. Taking this need into account, the prescription rates for these patients were remarkably low, ranging between $7.5 \%$ and $42.7 \%$. Furthermore, in patients with one or more comorbidities, room for improvement still exists in secondary preventive drug treatment.

\section{Revascularisation rates}

Many studies report lower revascularisation rates in women with CAD or acute coronary syndrome than in men with similar conditions [21-24]. These findings were confirmed by DETECT. Bertoni et al. [25] reported lower rates of coronary bypass surgery for women in the United States between 1995 and 2001, whereas the rates of catheterisation-based procedures were similar for both genders. Patients with private health care insurance in our study received PCI and coronary bypass surgery more often than CAD patients with social health insurance. This result is consistent with other studies that have found that insurance status appears to affect treatment in patients with acute myocardial infarction [26, 27].

Of course, one should keep in mind that lifestyle changes also play an important role in secondary prevention of coronary heart disease. Patients with established coronary heart disease are encouraged to stop smoking tobacco, make healthy food choices, increase physical activity, avoid excess weight, and reduce any existing excess weight [1]. 
antiplatelet agents

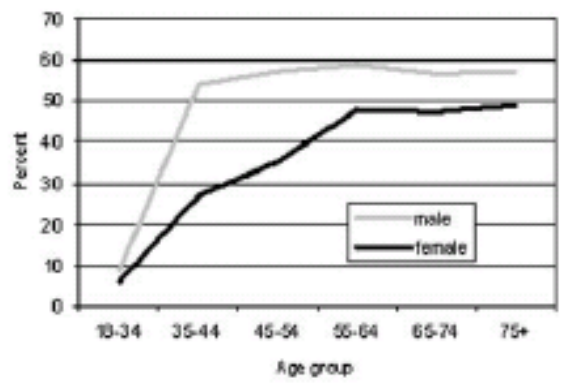

AT1 receptor antagonists

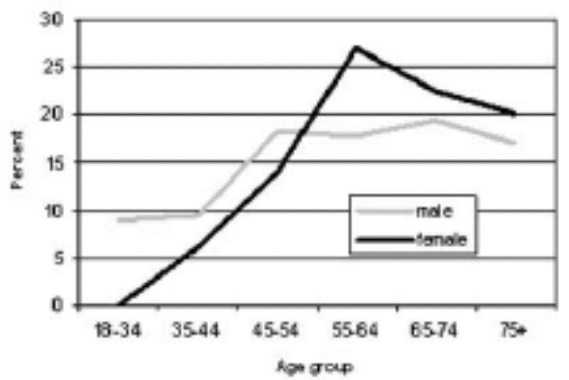

statins

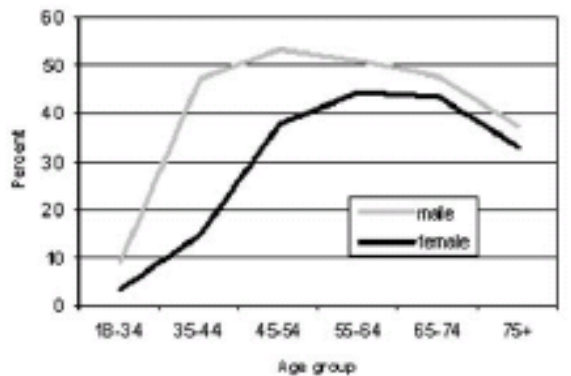

betablockers

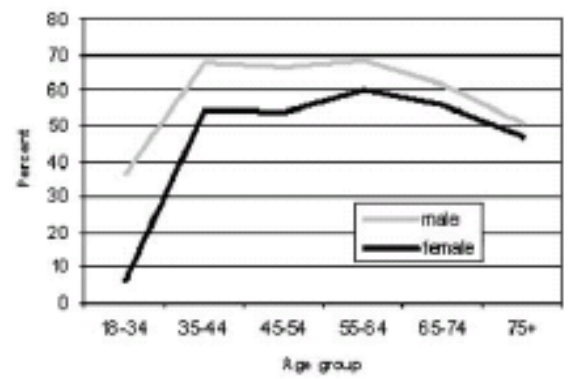

ACE inhibitors

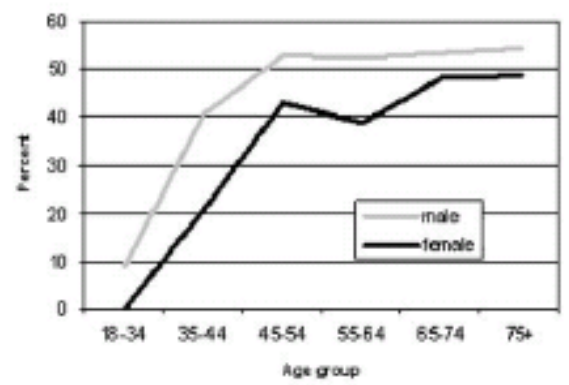

long-term nitrates

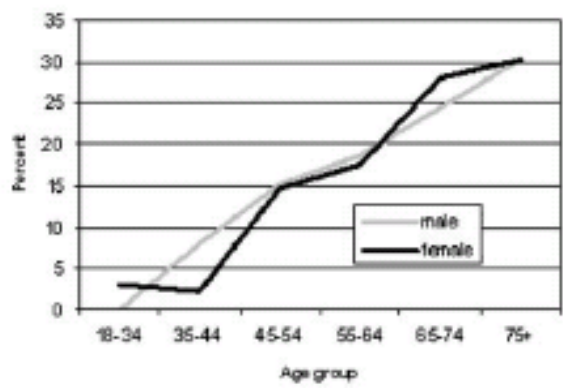

Fig. 1 Drferences in medication rates of CAD patients according to age and gender

Fig. 2 Prescription rates for medication groups by the number of comorbid diserses (diabetes me tus, hypertersion, and hyper pidaemial in patients with CAD

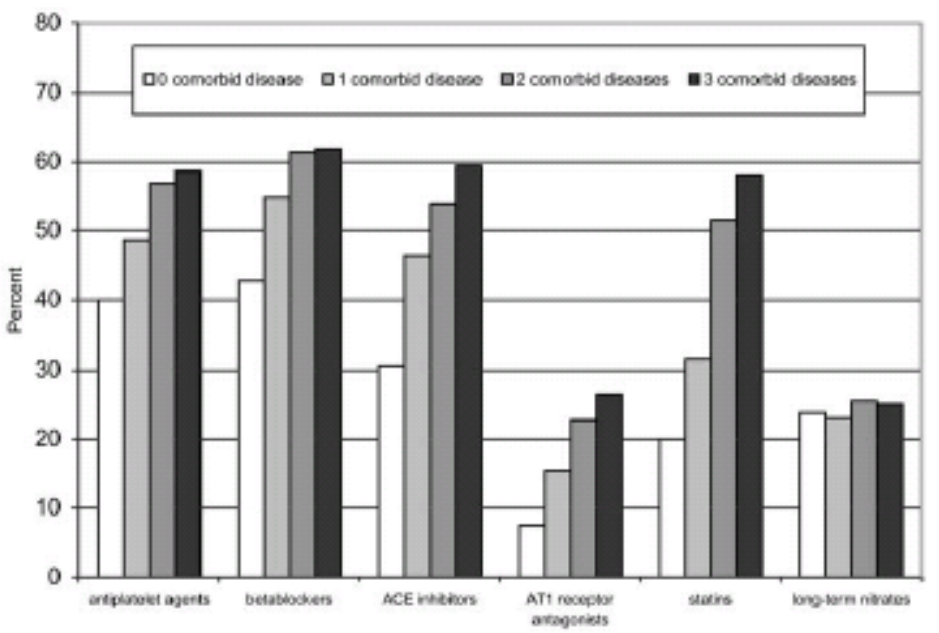


Fig. 3 Comparison of prevalence of CAD in ptmary care ofices (DETECT) and in the general populaton in Germary (Cerman Federal Surve, "Bundesgesundheitssurver'?. The DEECT study shows a sighty higher prevalence

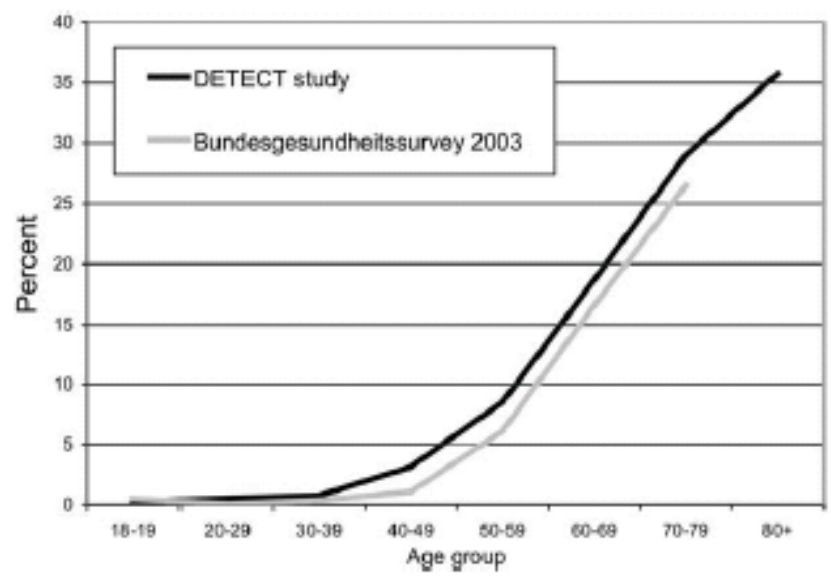

Table 1 Causes of death in Cermany

\begin{tabular}{|c|c|c|c|}
\hline & All & Male & Female \\
\hline German popuation on 31 Dec 2002 & 82536680 & 40344879 (49\%) & $42191801(519)$ \\
\hline Total dexth & 853946 (19) & $396270(0.994)$ & $45766(1.19)$ \\
\hline Dexth from cardovascular disease & $396622(4699)$ & $162210(41 \%)$ & $234412(519)$ \\
\hline Dexth from acute myocardial infarction & $64229(7.5 \%$ & $34689(8.89)$ & $29550(6.5 \%)$ \\
\hline Dexth from chronic ischaemic heart disease & 163445 (19.199) & 77123 (19.59) & $86322(18.9 \% 6)$ \\
\hline Dexth from CAD (xcute and chronic) & $22764(26.799)$ & 111802 (28.29) & 115872 (2539) \\
\hline Dexth from breast cancer & $17437(239$ & 264 & $17173(3.8 \%)$ \\
\hline Dexth from malignant tumours & $209255(24.59)$ & 110703 (27.999) & $98552(21.5 \%)$ \\
\hline
\end{tabular}

The latest data from the German Statstical Federal Bureau in Werbaden are from 2003 Statistsches Bundesamt Deutschland: http//www.destatis.de 2005)

Table 2 Prevalence of CAD and its subgroups in primary care in Germany by age and gender

\begin{tabular}{|c|c|c|c|c|c|c|c|c|c|c|c|c|}
\hline \multirow[t]{2}{*}{ Age groups } & \multicolumn{2}{|l|}{$C A D$} & \multicolumn{2}{|c|}{ Stable angina } & \multicolumn{2}{|c|}{ Unstable angina } & \multicolumn{2}{|c|}{$s / p M I$} & \multicolumn{2}{|c|}{$s / p P C$} & \multicolumn{2}{|c|}{$s / p C A B G$} \\
\hline & N & $\%$ & N & $\%$ & N & $\%$ & & $\%$ & N & $\%$ & N & $\%$ \\
\hline Total $N=55518$ & 6896 & 124 & 2353 & 42 & 627 & 1.1 & 2326 & 42 & 1638 & 30 & 1201 & 22 \\
\hline $18-34(\mathrm{~N}=8727)$ & 49 & 0.6 & 5 & 0.1 & 3 & 0.0 & 9 & 0.1 & 5 & 0.1 & 5 & 0.1 \\
\hline $35-4, N=8829)$ & 133 & 1.5 & 23 & 03 & 7 & 0.1 & 49 & 0.6 & 39 & 0.4 & 13 & 0.2 \\
\hline $45-54(\mathrm{~N}=9325)$ & 486 & 5.2 & 117 & 13 & 51 & 0.6 & 209 & 22 & 165 & 1.8 & 71 & 0.8 \\
\hline $55-64(\mathrm{~N}=10608)$ & 1397 & 13.2 & 397 & 37 & 146 & 1.4 & 517 & 4.9 & 402 & 3.8 & 253 & 24 \\
\hline $65-74 \mathrm{~N}=1155$ & 2736 & 23.7 & 949 & 82 & 232 & 20 & 932 & 81 & 657 & 5.7 & 534 & 4.6 \\
\hline $75+(N=6473)$ & 2094 & 324 & 862 & 133 & 188 & 29 & 610 & 9.4 & 370 & 5.7 & 325 & 5.0 \\
\hline Male $(\mathrm{N}=22679)$ & 3969 & 17.5 & 1218 & 5.4 & 316 & 1.4 & 1649 & 73 & 1169 & 5.2 & 915 & 40 \\
\hline $18-34(N=3243)$ & 15 & 0.5 & 0 & 00 & 1 & 0.0 & 5 & 0.2 & 2 & 0.1 & 1 & 0.0 \\
\hline $35-4 N=3334)$ & 78 & 23 & 14 & 0.4 & 3 & 0.1 & 40 & 1.2 & 30 & 0.9 & 9 & 03 \\
\hline $45-54(\mathrm{~N}=3781)$ & 323 & 8.5 & 75 & 20 & 34 & 0.9 & 153 & 4.1 & 129 & 3.4 & 60 & 1.6 \\
\hline $55-64(N=4716)$ & 981 & 19.7 & 245 & 52 & 8 & 1.7 & 403 & 8.6 & 319 & 6.8 & 214 & 45 \\
\hline $65-74(N=5189)$ & 1624 & 313 & 498 & 9.6 & 123 & 24 & 679 & 13.1 & 453 & 8.7 & 414 & 80 \\
\hline $75+(N=2416)$ & 998 & 413 & 386 & 160 & 73 & 3.0 & 369 & 153 & 236 & 9.8 & 217 & 90 \\
\hline Female $(\mathrm{N}=32839)$ & 2926 & 8.9 & 1135 & 3.5 & 311 & 1.0 & 677 & 21 & 469 & 1.4 & 286 & 0.9 \\
\hline $18-34(\mathrm{~N}=5484)$ & 34 & 0.6 & 5 & 0.1 & 2 & 0.0 & 4 & 0.1 & 3 & 0.1 & 4 & 0.1 \\
\hline $35-4 \quad(N=5495)$ & 55 & 10 & 9 & 02 & 4 & 0.1 & 9 & 0.2 & 9 & 0.2 & 4 & 0.1 \\
\hline $45-54(N=5544)$ & 163 & 29 & 42 & 0.8 & 17 & 0.3 & 56 & 1.0 & 36 & 0.7 & 11 & 0.2 \\
\hline $55-64(N=5892)$ & 466 & 7.9 & 152 & 26 & 64 & 1.1 & 114 & 1.9 & 83 & 1.4 & 39 & 0.7 \\
\hline $65-74(N=6367)$ & 1112 & 17.5 & 451 & 7.1 & 109 & 1.7 & 253 & 40 & 204 & 3.2 & 120 & 1.9 \\
\hline $75+N=4057)$ & 1096 & 27.0 & 476 & 11.7 & 115 & 28 & 241 & 5.9 & 134 & 33 & 108 & 27 \\
\hline
\end{tabular}

Data delved from 55518 patient. s'p status post, $M$ myocardial iffartion, PO percutaneous coronary intervention; CABG coronary artery bypass surgery 
Table 3 Medications used by patients with CAD (and it subgroups) in pamay care offices in Cermary

\begin{tabular}{|c|c|c|c|c|c|c|c|c|c|c|c|c|}
\hline & \multicolumn{2}{|c|}{$\begin{array}{l}C A D \\
N=6569)\end{array}$} & \multicolumn{2}{|c|}{$\begin{array}{l}\text { Stable angina } \\
(\mathrm{N}=2295)\end{array}$} & \multicolumn{2}{|c|}{$\begin{array}{l}\text { Unstable angina } \\
(N=613)\end{array}$} & \multicolumn{2}{|c|}{$\begin{array}{l}s / \mathrm{pMI} \\
(\mathrm{N}=2270)\end{array}$} & \multicolumn{2}{|c|}{$\begin{array}{l}5 / \mathrm{p} P Q \\
(\mathrm{~N}=1598)\end{array}$} & \multicolumn{2}{|c|}{$\begin{array}{l}s / p C A B C \\
N=1175)\end{array}$} \\
\hline & N & $\%$ & N & $\%$ & N & $\%$ & & $\%$ & N & $\%$ & $\mathrm{~N}$ & $\%$ \\
\hline Antiplatela agents & 3463 & 527 & 1180 & 51.4 & 277 & 45.2 & 1497 & 660 & 1149 & 71.9 & 791 & 673 \\
\hline Bea blockes & 3758 & 572 & 1187 & 51.7 & 334 & 54.5 & 1563 & 689 & 1196 & 74.8 & 870 & 740 \\
\hline ACE inhibitors & 3279 & 49.9 & 1102 & 480 & 331 & 540 & 1305 & 57.5 & 929 & 58.1 & 676 & 57.5 \\
\hline AT1 receptor antagonis ts & 1275 & 19.4 & 520 & 227 & 125 & 20.4 & 432 & 190 & 346 & 21.7 & 243 & 207 \\
\hline Stzins & 2824 & 48.0 & 894 & 39.0 & 257 & 41.9 & 1331 & 586 & 1055 & 660 & 764 & 65.0 \\
\hline Long-term nitrates & 1609 & 245 & 694 & 302 & 188 & 30.7 & 625 & 27.5 & 447 & 28.0 & 286 & 243 \\
\hline
\end{tabular}

For abbreviators see Table 2

\begin{tabular}{|c|c|c|c|}
\hline Study & EUROASPIRE-I & EUROASPIRE-II & DEECT \\
\hline $\begin{array}{l}\text { Data collected dứng } \\
\text { yex(s) }\end{array}$ & $1995-1996$ & $1999-2000$ & 2003 \\
\hline $\begin{array}{l}\text { Number of patents } \\
\text { with } C A D\end{array}$ & $\mathrm{n}=3569$ & $\mathrm{n}=3379$ & $n=6569$ \\
\hline Antiplatela medication & $812 \%$ & $83.9 \%$ & $527 \%$ \\
\hline Bata blockes & $537 \%$ & $66.4 \%$ & $572 \%$ \\
\hline ACE inhibitors & $29.5 \%$ & $427 \%$ & $49.9 \%$ \\
\hline Statirs & $18.5 \%$ & $57.7 \%$ & $43.0 \%$ \\
\hline \multicolumn{4}{|c|}{$\begin{array}{l}\text { Nthough the EURPASPIRE I and II data reflect the medicators at discharge } \\
\text { from hospitals and DETECT reflects the medication after discharge in an out- } \\
\text { patent seting the presciption rates for antiplatet medication, beta Hock- } \\
\text { ers, and statins are stil lower than the average for discharge medications } \\
\text { Europe }\end{array}$} \\
\hline
\end{tabular}

\section{References}

1. De Backer G, Ambrosioni E, Borch-Johnsen K, Brotons C, Cifkova R, Dallongeville J, Ebrahim S, Faergeman O, Graham I, Mancia G, Manger Cats V, Orth-Gomer K, Perk J, Pyorala K, Rodicio JL, Sans S, Sansoy V, Sechtem U, Silber S, Thomsen T, Wood D (2003) Executive Summary: European guidelines on cardiovascular disease prevention in clinical practice. Third Joint Task Force of European and Other Societies on Cardiovascular Disease Prevention in Clinical Practice (executive summary). Eur Heart J 24:1601-1610

2. Koenig W (1998) Epidemiology of coronary heart disease. Z Kardiol 87 (Suppl 2):3-7

3. Statistisches Bundesamt Deutschland (2005) http://www.destatis.de

4. Silber S, Albertsson P, Aviles FF, Camici PG, Colombo A, Hamm C, Jorgensen E, Marco J, Nordrehaug JE, Ruzyllo W, Urban P, Stone GW, Wijns W (2005) Guidelines for percutaneous coronary interventions. The Task Force for Percutaneous Coronary Interventions of the European Society of Cardiology. Eur Heart J 26:804-847

5. Lenzen MJ, Boersma E, Bertrand ME, Maier W, Moris C, Piscione F, Sechtem U, Stahle E, Widimsky P, de Jaegere P, Scholte op Reimer WJ, Mercado N, Wijns W (2005) Management and outcome of patients with established coronary artery disease: the Euro Heart Survey on coronary revascularization. Eur Heart J 26:1169-1179

6. Daly CA, Clemens F, Sendon JL, Tavazzi L, Boersma E, Danchin N, Delahaye F, Gitt A, Julian D, Mulcahy D, Ruzyllo W, Thygesen K, Verheugt F, Fox KM (2005) The initial management of stable angina in Europe, from the Euro Heart Survey: a description of pharmacological management and revascularization strategies initiated within the first month of presentation to a cardiologist in the Euro Heart Survey of Stable Angina. Eur Heart J 26:1011-1022

7. Wittchen HU, Glaesmer H, März W, Stalla G, Lehnert H, Zeiher AM, Silber S, Koch U, Böhler S, Pittrow D, Ruf G (2005) Cardiovascular risk factors in primary care: methods and baseline prevalence rates - the DETECT program. Curr Med Res Opin 21:619-630

8. Böhler S, Glaesmer H, Pittrow D, Lehnert H, Stalla GK, Zeiher AM, März W, Silber S, Wehling M, Ruf G, Reinecke A, Wittchen HU (2004) Diabetes and cardiovascular risk evaluation and management 
in primary care: progress and unresolved issues - rationale for a nationwide primary care project in Germany. Exp Clin Endocrinol Diabetes 112:157-170

9. StataCorp., Stata Statistical Software, Release 8.0 (2003) College Station, TX: Stata Corporation 10. Knopf H (2004) Arzneimittelanwendung bei Frauen und Männern mit koronarer Herzkrankheit. Bundesgesundheitsbl - Gesundheitsforsch - Gesundheitsschutz 47:1051-1056

11. Equinox Group (2001) Stable Angina Epidemiology. Equinox Drug Assessment Library 12. Jaber WA, Lennon RJ, Mathew V, Holmes DR Jr, Lerman A, Rihal CS (2005) Application of evidence-based medical therapy is associated with improved outcomes after percutaneous coronary intervention and is a valid quality indicator. J Am Coll Cardiol 46:1473-1478

13. Silber S, Krischke I, Prohaska M (2000) Undertreatment in secondary prevention of patients with coronary heart disease after revascularization. Herz 25:623-626

14. The EUROASPIRE I and II Group (2001) Clinical reality of coronary prevention guidelines: a comparison of EUROASPIRE I and II in nine countries. EUROASPIRE I and II Group. European Action on Secondary Prevention by Intervention to Reduce Events. Lancet 357:995-1001

15. Brady AJB, Oliver MA, Pittard JB (2001) Secondary prevention in 24431 patients with coronary heart disease: survey in primary care. BMJ 322:1463

16. Abuful A, Gidron Y, Henkin Y (2005) Physician's attitudes toward preventive therapy for coronary artery disease: Is there a gender bias? Clinical Cardiology 28(8):389-393

17. Hippisley-Cox J, Pringle M, Crown N, Meal A, Wynn A (2001) Sex inequalities in ischaemic heart disease in general practice: cross sectional survey. BMJ 322:832

18. Sheifer SE, Escarce JJ, Schulman KA (2000) Race and sex differences in the management of coronary artery disease. American Heart Journal 139(5):848-857

19. Schwartz JB (2003) Gender-specific implications for cardiovascular medication use in the elderly optimizing therapy for older women. Cardiol Rev 11:275-298

20. Os I, Bratland B, Dahlhof B, Gisholt K, Syvertsen JO, Tretli S (1994) Female preponderance for lisinopril-induced cough in hypertension. Am J Hypertens 7(11):1012-1015

21. Blomkalns AL, Chen AY, Hochman JS, Peterson ED, Trynosky K, Diercks DB, Brogan GXJ, Boden WE, Roe MT, Ohman EM, Gibler WB, Newby LK, CRUSADE I (2005) Gender disparities in the diagnosis and treatment of non-ST-segment elevation acute coronary syndromes: large-scale observations from the CRUSADE (Can Rapid Risk Stratification of Unstable Angina Patients Suppress Adverse Outcomes With Early Implementation of the American College of Cardiology/American Heart Association Guidelines) National Quality Improvement Initiative. J Am Coll Cardiol 45(6):832-837

22. Doyle F, De La Harpe D, McGee H, Shelley E, Conroy R (2005) Gender differences in the presentation and management of acute coronary syndromes: a national sample of 1365 admissions. Eur J Cardiovasc Prev Rehabil 12(4):376-379

23. Heer T, Schiele R, Schneider S, Gitt AK, Wienbergen H, Gottwik M, Gieseler U, Voigtlander T, Hauptmann KE, Wagner S, Senges J (2002) Gender differences in acute myocardial infarction in the era of reperfusion (the MITRA registry). Am J Cardiol 89(5):511-517

24. Schulman KA, Berlin JA, Harless W, Kerner JF, Sistrunk S, Gersh BJ, Dubé R, Taleghani CK, Burke JE, Williams S, Eisenberg JM, Escarce JJ, Ayers W (1999) The effect of race and sex on physicians' recommendations for cardiac catheterization. N Engl J Med 25; 340(8):618-626 25. Bertoni AG, Bonds DE, Lovato J, Goff DC, Brancati FL (2004) Sex disparities in procedure use for acute myocardial infarction in the United States, 1995 to 2001. Am Heart J 147(6):1054-1060 26. Yu BR (2005) Influences of health insurance status on clinical treatments and outcomes for 4714 patients after acute myocardial infarction in 14 Chinese general hospitals. J Med Dent Sci 52(2):143151

27. Hiestand BC, Prall DM, Lindsell CJ, Hoekstra JW, Pollack CV, Hollander JE, Tiffany BR, Peacock WF, Diercks DB, Gibler WB (2004) Insurance status and the treatment of myocardial infarction at academic centers. Acad Emerg Med 11(4):343-348 